\title{
Can heterogeneity in ventilation be good?
}

\author{
Eduardo LV Costa,2 and Marcelo BP Amato*2 \\ See related research by Zhao et al., http://ccforum.com/content/14/1/R8
}

\begin{abstract}
Selection of the optimal positive end-expiratory pressure (PEEP) to avoid ventilator-induced lung injury in patients under mechanical ventilation is still a matter of debate. Many methods are available, but none is considered the gold standard. In the previous issue of Critical Care, Zhao and colleagues applied a method based on electrical impedance tomography to help select the PEEP that minimized ventilation inhomogeneities. Though promising when alveolar collapse and overdistension are present, this method might be misleading in patients with normal lungs.
\end{abstract}

In the previous issue of Critical Care, Zhao and colleagues [1] applied a method based on electrical impedance tomography (EIT) to help select the positive endexpiratory pressure (PEEP) that minimized ventilation inhomogeneities in healthy lungs. Several methods, including those based on global mechanics [2,3], arterial blood gases [4], x-ray computerized tomography (CT) [5], and EIT [6,7], have been proposed to select the best PEEP in patients under mechanical ventilation. Each of these methods has advantages and disadvantages, and none is considered the gold standard. Lung compliance, for example, is the result of an interplay between overdistension and lung collapse. Not infrequently, in PEEP versus compliance curves, the relief of overdistension after a PEEP reduction overshadows the appearance of massive lung collapse. Conversely, CT provides excellent anatomical resolution and allows precise quantification of lung collapse but with the inconveniences of using ionizing radiation and requiring that patients be transferred out of the intensive care unit. EIT has a lower spatial resolution but is radiation-free and can be used at the bedside for prolonged periods of time. EIT provides

\footnotetext{
*Correspondence: amato@unisys.com.br

2Respiratory Intensive Care Unit, University of São Paulo School of Medicine, Av Dr Arnaldo, 455, Room 2206 (2nd floor), 01246-903, São Paulo, SP, Brazil Full list of author information is available at the end of the article
}

information on the regional ventilation of a cross-section of the thorax and can be used to assess changes in regional ventilation that follow changes in PEEP [7] and to estimate lung collapse and overdistension [6].

In patients with acute lung injury/acute respiratory distress syndrome (ALI/ARDS), lung collapse occurs predominantly in dependent regions, and tidal hyperinflation commonly follows in the remaining aerated zones, especially when there is a large nonaerated compartment [8]. Therefore, ALI/ARDS is characterized by inadequate distribution of ventilation with a relatively small number of normal alveoli receiving most of the tidal volume, a phenomenon that promotes high cyclic stress concentrated in a few lung units, probably triggering further parenchymal injury. In these patients, recruitment maneuvers followed by careful selection of the PEEP can reopen collapsed lung units and prevent their end-expiratory collapse [5]. These reopened units can improve the ventilation distribution by accommodating part of the tidal volume, thus minimizing tidal hyperinflation as well. In this context, homogenization of lung ventilation became synonymous with protecting the lungs. Conversely, in normal lungs with minimal collapse, heterogeneity of lung ventilation is a physiologic phenomenon $[9,10]$, with the dependent lung regions (along the gravity axis) presenting higher regional ventilation because of a more favorable mechanical condition. Gravity necessarily imposes some pretensioning to the nondependent lung units, causing a lower resting compliance. Such heterogeneity mirrors the heterogeneity of lung perfusion, and this matching between the gradients of ventilation and perfusion seems essential to the optimization of gas exchange. Therefore, attempts to minimize the heterogeneity in ventilation of the normal lung might not be helpful or might even be deleterious.

Zhao and colleagues [1] studied 10 patients with healthy lungs in whom PEEP was titrated according to an index of global inhomogeneity of ventilation based on EIT. PEEP was increased from 0 to $28 \mathrm{mbar}$, and the global inhomogeneity index was calculated for each step. Optimal PEEP was defined as the pressure that led to the lowest inhomogeneity and was not statistically different from the PEEP titrated according to the maximal dynamic compliance or to the compliance-volume curve methods. 
The agreement among the three methods, however, was poor, and differences in the titrated PEEP according to each method were up to 10 mbar.

The study has some limitations, the first of which are the lack of lung recruitment maneuvers and the use of incremental as opposed to decremental PEEP titration. An effective lung recruitment to reverse as much collapse as possible and a decremental PEEP titration to select the lowest pressure that maintained the alveoli open would have yielded the best compromise between collapse and overdistension [11] and perhaps would have led to a different 'optimal PEEP'. Second, the global inhomogeneity index is highly dependent on the lung area of interest [12], and the lung area estimation method used may not contemplate regions with bilateral collapse. Finally, and most importantly, because a certain degree of heterogeneity may be considered physiologic, it is uncertain whether the heterogeneity of ventilation should be minimized in patients with healthy lungs.

In summary, a method to help tailor PEEP values at the bedside is long overdue. Zhao and colleagues have brought to focus the importance of assessing regional ventilation distribution. Such knowledge is welcome and is essential to understand the relative contributions of lung collapse and overdistension to the global lung function and ultimately to the phenomenon of ventilatorinduced lung injury.

Abbreviations

ALI/ARDS, acute lung injury/acute respiratory distress syndrome; CT, computerized tomography; EIT, electrical impedance tomography; PEEP, positive end-expiratory pressure.

\section{Competing interests}

MA has received research grants from Dixtal Biomédica Ltda (São Paulo, Brazil) in the last 3 years. EC declares that he has no competing interests.

\section{Author details}

'Research and Education Institute, Hospital Sírio Libanês, Rua Cel. Nicolau dos Santos, 69, 01308-060, São Paulo, SP, Brazil. ${ }^{2}$ Respiratory Intensive Care Unit, University of São Paulo School of Medicine, Av Dr Arnaldo, 455, Room 2206 (2nd floor), 01246-903, São Paulo, SP, Brazil.
Published: 22 March 2010

\section{References}

1. Zhao Z, Steinmann D, Frerichs I, Guttmann J, Möller K: PEEP titration guided by ventilation homogeneity: a feasibility study using electrical impedance tomography. Crit Care 2010, 14:R8

2. Amato MB, Barbas CS, Medeiros DM, Magaldi RB, Schettino GP, Lorenzi-Filho G, Kairalla RA, Deheinzelin D, Munoz C, Oliveira R, Takagaki TY, Carvalho CR: Effect of a protective-ventilation strategy on mortality in the acute respiratory distress syndrome. N Engl J Med 1998, 338:347-354.

3. Suarez-Sipmann F, Böhm SH, Tusman G, Pesch T, Thamm O, Reissmann H, Reske A, Magnusson A, Hedenstierna G: Use of dynamic compliance for open lung positive end-expiratory pressure titration in an experimental study. Crit Care Med 2007, 35:214-221.

4. Hedenstierna G, Tokics L, Strandberg A, Lundquist H, Brismar B: Correlation of gas exchange impairment to development of atelectasis during anaesthesia and muscle paralysis. Acta Anaesthesio/ Scand 1986, 30:183-191.

5. Borges JB, Okamoto VN, Matos GF, Caramez MP, Arantes PR, Barros F, Souza CE, Victorino JA, Kacmarek RM, Barbas CS, Carvalho CR, Amato MB: Reversibility of lung collapse and hypoxemia in early acute respiratory distress syndrome. Am J Respir Crit Care Med 2006, 174:268-278.

6. Costa EL, Borges JB, Melo A, Suarez-Sipmann F, Toufen C Jr., Bohm SH, Amato MB: Bedside estimation of recruitable alveolar collapse and hyperdistension by electrical impedance tomography. Intensive Care Med 2009, 35:1132-1137.

7. Meier T, Luepschen H, Karsten J, Leibecke T, Grossherr M, Gehring H, Leonhardt S: Assessment of regional lung recruitment and derecruitment during a PEEP trial based on electrical impedance tomography. Intensive Care Med 2008, 34:543-550.

8. Terragni PP, Rosboch G, Tealdi A, Corno E, Menaldo E, Davini O, Gandini G, Herrmann P, Mascia L, Quintel M, Slutsky AS, Gattinoni L, Ranieri VM: Tidal hyperinflation during low tidal volume ventilation in acute respiratory distress syndrome. Am J Respir Crit Care Med 2007, 175:160-166.

9. Vawter DL, Matthews FL, West JB: Effect of shape and size of lung and chest wall on stresses in the lung. J Appl Physio/ 1975, 39:9-17.

10. West JB, Matthews FL: Stresses, strains, and surface pressures in the lung caused by its weight. J App/ Physiol 1972, 32:332-345.

11. Hickling KG: Best compliance during a decremental, but not incremental, positive end-expiratory pressure trial is related to open-lung positive end-expiratory pressure: a mathematical model of acute respiratory distress syndrome lungs. Am J Respir Crit Care Med 2001, 163:69-78.

12. Zhao Z, Möller K, Steinmann D, Frerichs I, Guttmann J: Evaluation of an electrical impedance tomography-based Global Inhomogeneity Index for pulmonary ventilation distribution. Intensive Care Med 2009, 35:1900-1906.

doi:10.1186/cc8901

Cite this article as: Costa ELV, Amato MBP: Can heterogeneity in ventilation be good? Critical Care 2010, 14:134. 